\title{
EFFECT OF CYCLE OF LOADING ON SUBBASE FRICTION CHARISARITICS UNDER RIGID PAVEMENT
}

\author{
*Thulfiqar A. Aboaljus ${ }^{1}$ \\ Qais S. Banyhussan ${ }^{1}$ \\ Mohammed H. Mohammed ${ }^{1}$
}

1) Highway and Transportation Engineering Department, College of Engineering, Mustansiriyah University, Baghdad, Iraq

\begin{abstract}
The coefficient of friction is a measurement of the frictional force between two objects. As the temperature of the pavement changes, it might slide against the resistance of the supporting subbase. In order for pavement to perform as anticipated, this resistance must be calculated. Concrete cracking does not occur when the pavement is joined. A membrane layer is positioned between the subbase and the plate in joint plain concrete pavements to smooth the interface. The displacement of concrete caused by temperature differences is less resistant on a smooth surface. For subbase conditions, two stages of the push-off test were performed (smooth and rough) to show the effects of movement cycles. Based on the results of the friction tests, the friction properties of the concrete and subbase were investigated. The parameters that influence the coefficient of friction and displacement are (interface state, movement rate, thickness number of movement cycles), changing the interface condition from smooth to rough leads to an increase the FRF of $(6,9$ and $12 \mathrm{~cm} / \mathrm{hr})$ by $(194.7,194.4$ and $189.8 \%)$ respectively. Finally, once the applied force reaches a stable state, the frictional force increases dramatically. The most important influence on this force is the interface state, which is accompanied by movement rate and thickness. The variation of the relationship curves with number of cycles tends to be insignificant after the third to fourth cycle of slab movement.
\end{abstract}

Keywords: joint plain concrete pavement; push-off test; subbase; slab; displacement; friction.

\section{Introduction}

The classical perspective of friction has described it as frictional resistance. It can be obtained by finding the laterally applied force $(\mathrm{P})$ that applies to the object's weight (W), which is equal to or less than the frictional resistance. $(\mathrm{N})$ Represent the reactions to these forces as illustrated in Fig. 1. The frictional resistance increases as long as an applied force increases, and they stay in an equilibrium state until the maximum value of laterally applied force. This maximal value is generally mentioned as the statical friction coefficient, which can be obtained by dividing $(\mathrm{P})$ by $(\mathrm{W})$. Once exceeding the maximum frictional resistance force, the block begins to move. The frictional resistance drops to its maximum dynamic frictional resistance. The dynamic friction factor will permanently be less than the static friction factor. They could be calculated using a similar method [1]. The features of these coefficients seem to be: applied force independently, independent of the area of the contacting surfaces, and dependent on the nature of the surfaces in contact and the exact condition of the surfaces [2].

When a concrete plate contract because of a decrease of temperature, humidity decline or concrete creeping, the frictional forces generated.

*Corresponding Author: edma011@uomustansiriyah.edu.iq 


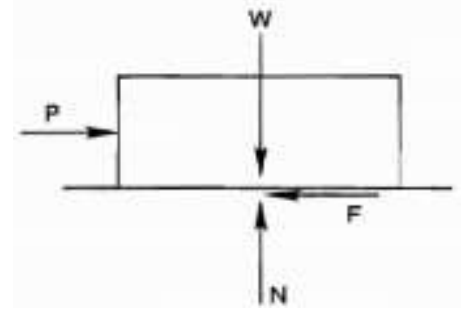

Figure 1. Classical friction model [2]

Once that happen, the interface's friction resists the movements. Movement resistance contributes to producing direct tensile stress in the concrete .

The slab's movements rise from zero at the centre to maximum at the edges. The tensile stresses formed within the plate by the restraint decline from a maximum at the centre to zero at the free edges. Since the movements frictional resistance grow from the slab ends. The higher restraint, lead to higher generated tensile stresses along whole length of concrete plate. Those tensile stresses are essential since they could be additional to those tensile stresses caused by road traffic and restrained thermic wrapping to such a degree that the plate would crack [1]. As concrete seems to have a weak tensile strength, the production of even minor tensile stresses due to shrinkage can often lead to cracking inside the restrained concrete components. Cracking decreases the load-bearing capacity of the concrete parts, results in the deterioration of the steel reinforcement, raises the risk of alkali-silica reactions and sulfate attacks, and causes other durability conflicts leading to the increased cost of maintenance and decreased service life. The algorithm's main parts have been widely described in [3].

Many researchers examined the interlayer friction properties between the concrete pavement and the sub-base by performed pushoff tests. The method implemented in the previous push-off test has been mainly for calculating the concrete test slabs' displacements throughout the application of the horizontal forces which inducting the movements. [4] and [5] have noticed that varying $\mu$-displacement relationship from the first slab displacement cycle to the second one is considerable. However, varying $\mu$-displacement relationship with several cycles has the tendency of being insignificant following the third to fourth slab displacement cycle. Smoothening the sliding plane has been considered as one of the potential causes for decreased $\mu$ and increased preliminary displacement with a number of the slab movement cycles. [1] observed the sliding plane's direction. The sliding plane has been noticed at the slab-base interface in loose, unbound base situations, such as loam, clay, and granular base.

\section{The Aim and Objectives For This Study}

The main aim of this work is to calculate the coefficient of friction and compare it to the following cycles of lateral push forces. To catch the aim of the study, the push-off test has carried out with three variables (rate movement, slab thickness, interface condition).

\section{Materials Used}

\subsection{Concrete}

Concrete with a compressive strength of (31 MPa in 28 days) was used. The proportions of the mixture (i.e., the cement, sand, and gravel) adopted for the concrete slabs were (1:2.2:3.2) based on the properties described by [6], as shown in table 1 , which achieves a compressive strength of more than $30 \mathrm{MPa}$. The mix proportions are illustrated in table 1 with a maximum aggregate size of $19 \mathrm{~mm}$, both coarse and fine aggregate match gradation according to [7]. 
Table 1. Mixture Proportion of Concrete Slabs.

\begin{tabular}{cccc}
\hline & \multicolumn{2}{c}{ Unit $(\mathrm{kg} / \mathrm{m} 3)$} \\
Water & Cement & Fine & Coarse \\
140 & 350 & 775 & 1135 \\
\hline Slump (mm) & \multicolumn{2}{c}{ Water/Cement (\%) } & Fine Agg. \% \\
60 & & 40 & 40 \\
\hline
\end{tabular}

\subsection{Sub-Base}

Type A sub-base layer was used and compacted, (200 mm) thickness subbase granular material (SGM), which satisfies the specification grading accordance with [7] and limits of type A.

\subsection{Polyethylene Sheet}

A $(125 \mu \mathrm{m})$ thick polyethylene nylon layer was placed under the slabs for smooth friction.

\section{Push-off Test}

The push-off test was conducted at the Materials Lab in College of Engineering/ Civil Engineering Department of Mustansiriyah University; the field test has been carried out in a testing box inside $(4.1 \mathrm{~m})$ long $(2.1 \mathrm{~m})$ width. The subbase layer in the box has been granular materials laid in the box's entire area, as shown in the 3dimensional diagram of the testing room Fig. 2. The push-off test has been conducted by concrete slabs, which have been put on the top of various interface types. Two different interface conditions have been given; the testing slab has been directly cast on SGM.

One layer of a polyethylene sheet has been located between the test slab and the subbase layer. The temperature during the test was approximately $\left(16.9-28.9 \mathrm{C}^{\mathrm{o}}\right)$. Various studies have used the push-off test in the last decades, but only one local study was conducted by [8].

As illustrated in Fig. 2, three concrete slabs of $(1000 * 500 \mathrm{~mm})$ for length and width, respectively with three different thicknesses $(100,150$ and $200 \mathrm{~mm})$ were (concrete slab directly cast on SGM, and a polyethylene sheet placed between concrete slab and subbase layer). The experiments were carried out for the rough interface (with no polyethylene sheet) and smooth interface with polyethylene sheet laid between slab and subbase layer. The series of various parameters that have been taken under consideration in the experiential program are listed in table 2. A total of eighteen slabs have been cast. Every six slabs represent series were included three slabs with a smooth interface and three slabs with a rough interface of the same thickness. The current study used one type of subbase and two interface conditions.

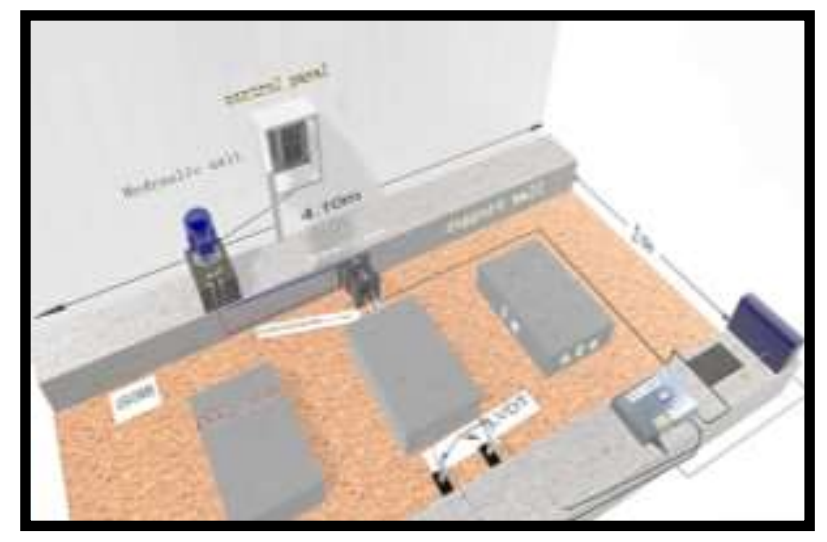

Figure 2. 3-dimensional diagram of the testing room.

Table 2. Details of Experimental Series

\begin{tabular}{lllc}
\hline $\begin{array}{l}\text { Subbase } \\
\text { Type }\end{array}$ & $\begin{array}{l}\text { Slab } \\
\text { thickness } \\
(\mathrm{mm})\end{array}$ & $\begin{array}{l}\text { Type of } \\
\text { Interfaces }\end{array}$ & $\begin{array}{l}\text { Slabs } \\
\text { Number }\end{array}$ \\
\hline 200mm & 100 & Smooth & 3 \\
thick & 100 & Rough & 3 \\
Granular & 150 & Smooth & 3 \\
Materials & 150 & Rough & 3 \\
& 200 & Smooth & 3 \\
& 200 & Rough & 3 \\
\hline
\end{tabular}

A hydraulic jack supported on the testing box's support wall has been utilized for the push-off test. The horizontally applied force has been evaluated using a load cell of $(50 \mathrm{KN})$ capacity as shown in plate 1 . The slabs roughly attached 
to the subbase were pushed by a hydraulic jack of (200 KN) capacity. The slab's horizontal displacement was monitored with two linear variable differential transformers (LVDT) (an electrical converter used to calculate linear displacement). The experimental test slab setups with the hydraulic jack, (LVDT), load cell, data logger, and computer were similar approaches used previously by [8].

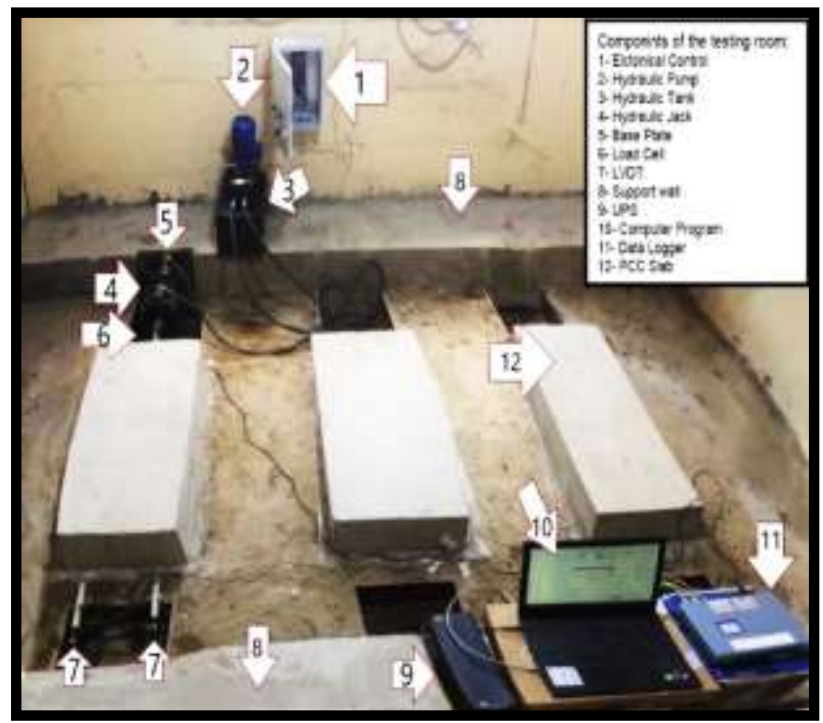

Plate 1. Slabs test with a hydraulic jack, pump, load cell, (LVDT), data logger, and computer, as well as other parts

For slabs with a smooth interface, a $(125 \mu \mathrm{m})$ thick polyethylene sheet has been laid flat with no creases over SGM before pouring the concrete slab. The push-off test has been carried out by applying the horizontal force on slabs. For every one of the series, the push-off test was conducted in three different movement rates $(6,9$, and $12 \mathrm{~cm} / \mathrm{h}$ ); the mean value of displacements was recorded by two (LVDT), which represent slab displacement.

\section{Results and Discussions}

\subsection{Friction Resistance Force (FRF) versus Displacement Curves}

For this push-off test series, several cycles were accomplished. The variation of FRF with sliding displacement for one type of the subbase granular material (SMG) and two interface conditions acquired for various load cycles. "C" represents the cycle of loading, the first numeral following the "C" cycle number, while the second numeral loading application side " 1 " for a push from the right and " 2 " for a push from the left. It has been observed the initial bond was broken; it will be easy pushing that slab in the following cycles, with a FRF slowly reducing and lastly reach steady-state condition. Fig. 3 shows the FRF with displacement relationships for one slab with the thickness of $(20 \mathrm{~cm})$, movement rate $(6 \mathrm{~cm} / \mathrm{hr})$, and smooth interface. From the maximum FRF against displacement relationships, the results of the push-off tests are shown in table 3 . The results

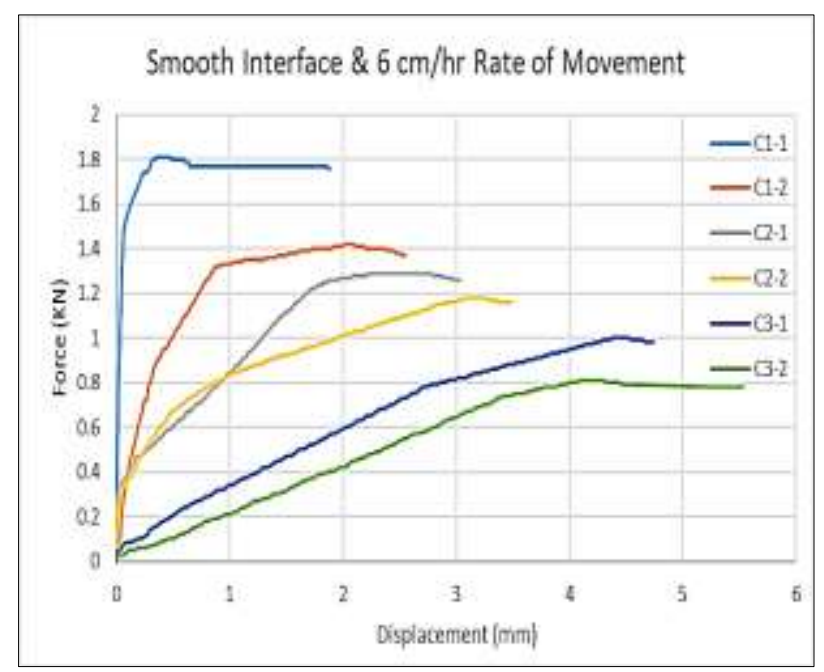

Figure 3. Comparison of FRF and disp. with (S20a6)

show the displacement and its corresponding maximum FRF for two types of interface conditions (i.e., smooth and rough), three slabs' thicknesses, and three rates of movements. The coefficient of friction at slab interface and subbase in every one of the cycles has been computed from the (equation 1):

$\mu=F / N$

$\mu=$ Coefficient of friction.

$N=$ Weight of the slab, $(\mathrm{KN})$.

$F=$ Friction resistance force required for pushing the slab, $(\mathrm{KN})$. 
Table 3. Results of Push-off Test of Friction Characteristics $(20 \mathrm{~cm})$ Slabs Thickness

\begin{tabular}{cccc}
\hline $\begin{array}{c}\text { Rate of } \\
\text { movement }\end{array}$ & $\begin{array}{c}\text { Type of } \\
\text { Interfaces }\end{array}$ & $\begin{array}{c}\text { Initial Cycle } \\
(\mathrm{KN})\end{array}$ & $\begin{array}{c}\text { Following } \\
\text { Cycles } \\
(\mathrm{KN})\end{array}$ \\
\hline $6 \mathrm{~cm} / \mathrm{hr}$. & Smooth & 1.81 & $1.42-0.81$ \\
& Rough & 7.26 & $5.44-2.00$ \\
$9 \mathrm{~cm} / \mathrm{hr}$. & Smooth & 1.92 & $1.48-0.88$ \\
& Rough & 7.48 & $5.92-2.44$ \\
$12 \mathrm{~cm} / \mathrm{hr}$. & Smooth & 2.01 & $1.71-0.94$ \\
& Rough & 7.63 & $6.12-2.85$ \\
\hline
\end{tabular}

\subsection{Variation of FRF with Cycles}

The slab is pushed from two responding directions with a comparable arrangement of the loading, one by one completing one cycle, to represent the temperature changing for the surrounding environment of the rigid pavement. With regard to every one of the slabs, the load has been applied for some cycles to the point of the stabilization of the applied horizontal loads. In addition, it is indicated that the FRF was decreasing with every one of the consecutive cycles regarding the application of the load, similar approaches found in [9]. As shown in Fig. 4 , Fig. 5 and Fig. 6 , the cycles ageist maximum force curves, the curve slope start at the maximum value since there is initially more bonding between concrete slab and subbase, then it starts decline by the next cycles. The decline slope for the rough interface is higher than the smooth interface for all thicknesses. Smooth interface is almost the same in all thicknesses because the bonding is the same between polyethylene sheet and the concrete slab, the weight of the slab here effect more than the friction between subbase and slabs.

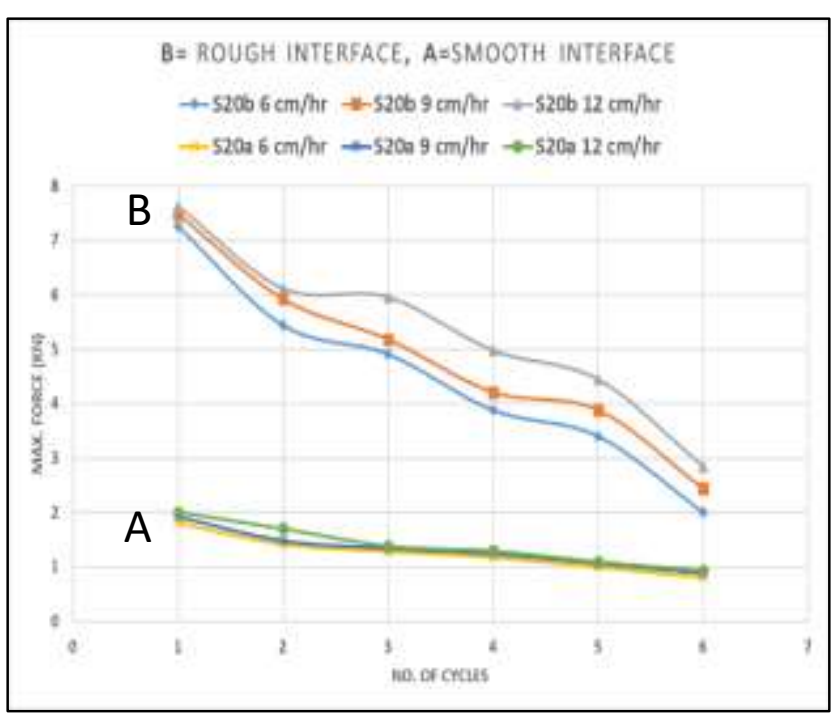

Figure 4. Variation of FRF and cycles (20 cm thickness)

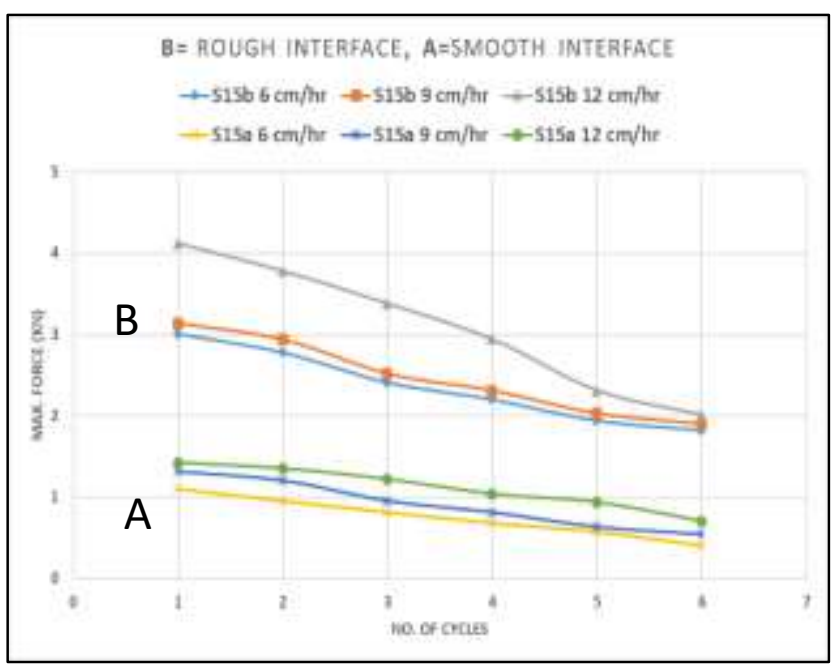

Figure 5. Variation of FRF and cycles (15 cm thickness)

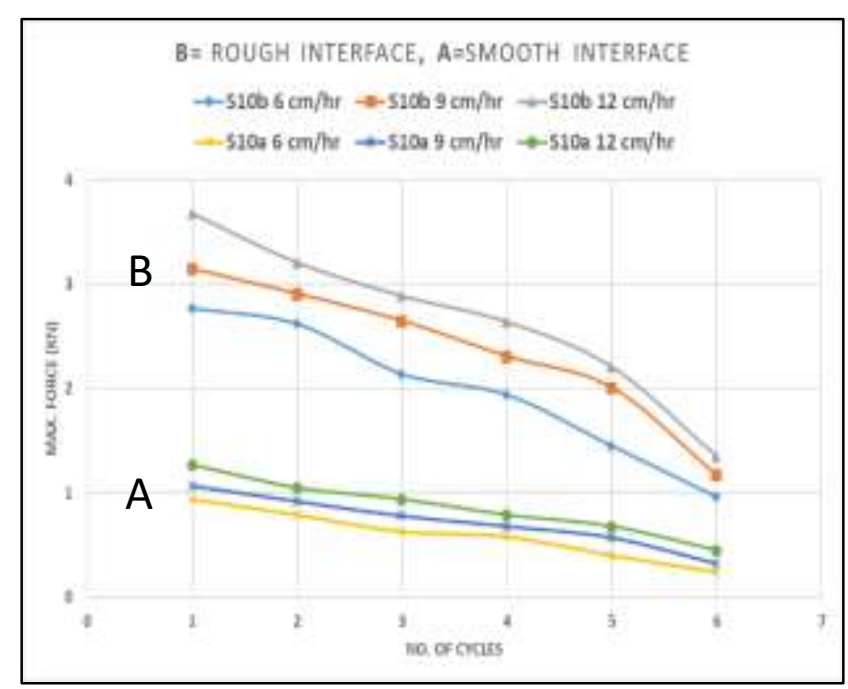

Figure 6. Variation of FRF and cycles (10 cm thickness) 


\subsection{Screening and Variables Analysis of Subbase Friction}

Screening analysis used to investigate the influence regarding the set of variables on predicted the FRF for choosing the major contributing variables. As proposed by [10], Design of experiment DoE is utilized in this work with outcomes providing utilizing the Pareto chart. The chart is showing the major parameters impacting the FRF, that is displayed in Fig. 7, the interface condition has the most significant impact followed by thickness and the rate of movement.

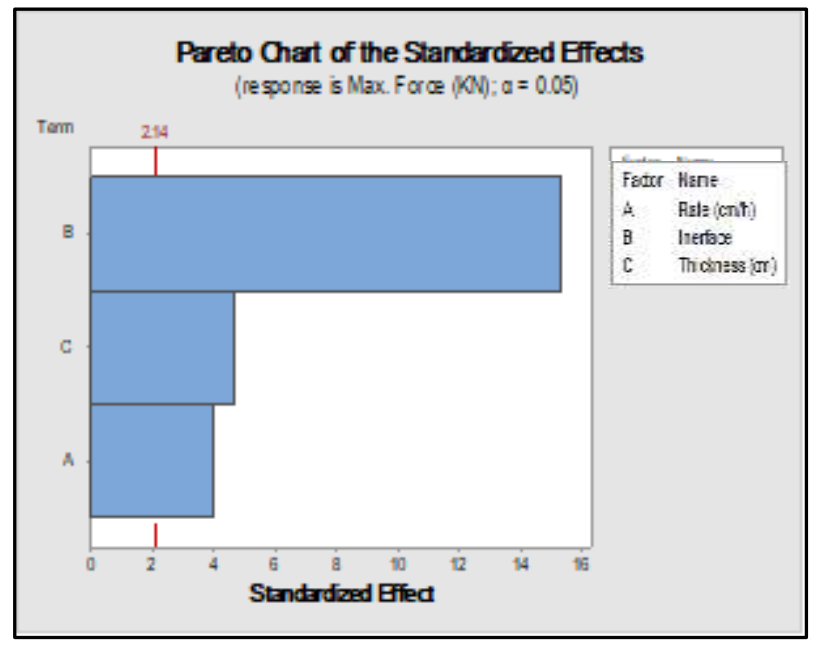

Figure 7. Results of screening analyses for FRF

\subsection{Effect of Interface, Thickness, and Rate of Movement on the FRF}

After doing the screening, it was found that interface condition is the higher factor affecting on the FRF followed by the slab thickness and the rate of movement, as shown in Fig. 7. The experimental results indicated that the FRF increases by changing the interface condition from smooth to rough and increasing slab thickness showed more compliant, as listed in table 3 .

In general, the change interface condition from smooth to rough leads to an increase in the FRF regardless of raise slab thickness or rate of movement, as shown in Fig. 8. For example, at $(10 \mathrm{~cm})$ slab thickness with changing the interface condition from smooth to rough leads to an increase the FRF of $(6,9$ and $12 \mathrm{~cm} / \mathrm{hr})$ by (194.7, 194.4 and $189.8 \%$ ) respectively. The findings are matching with previous works [7]. As regards increase the slab thickness leads to growth in the FRF regardless of change interface condition or rate of movement, as shown in Fig. 8. For instance, increasing slab thickness for $(10$ $\mathrm{cm})$ and $(20 \mathrm{~cm})$ at smooth interface condition for $(6,9$ and $12 \mathrm{~cm} / \mathrm{hr}$ ) leads to increase the FRF by (92.6, 79.4 and $58.3 \%$ ) respectively, while at rough interface condition by (162.1, 137.5 and $107.3 \%)$ respectively. The findings are matching with previous studies by [1] and [5].

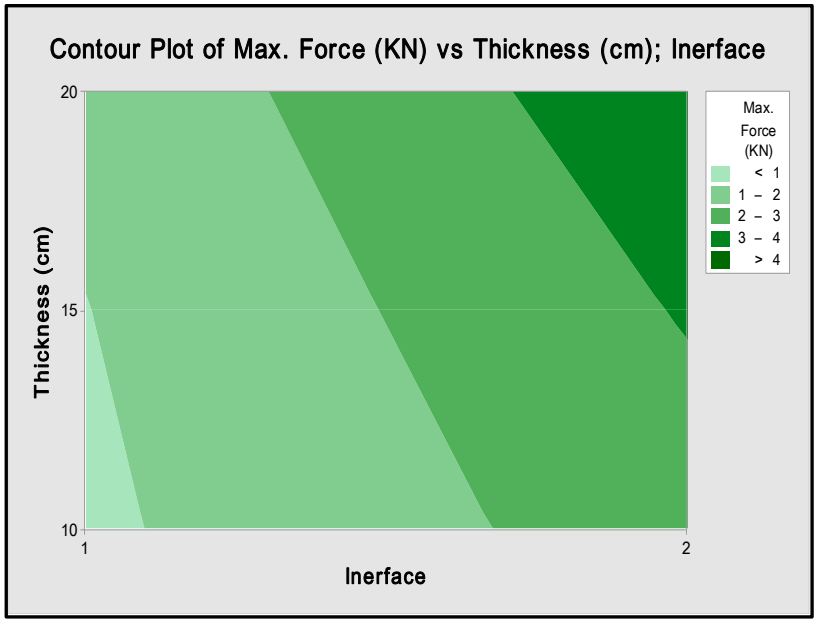

Figure 8. Effect of slab thickness and interface on FRF

\section{Conclusions}

1. The initial FRF will not change significantly regardless of the raise slab thickness or movement rate, where both of these factors below the influence line of screening analysis.

2. The maximum value of friction resistance force represents by the initial FRF detected in the primary force application.

3. Changing interface conditions from smooth to rough leads to increased friction resistance forces of $(6,9$ and $12 \mathrm{~cm} / \mathrm{hr})$ by $(194.7,194.4$ and $189.8 \%$ ) respectively due to surface 
texture and high gradation of type A subbase and reduced initial displacement because removing the separator layer will create more interlock between surfaces.

4. Relating the interface condition, when smooth interface the movement rate has almost no effect on the coefficient of friction, but it grows with the rising of movement rate in rough condition.

5. Subsequent attempts of cycles are always less than the first cycle.

6. In smooth condition, the polythene film will be attached to the slab's bottom, thus creating a smooth surface for the slab to slip above the subbase, leading to less friction.

7. If a failure occurs at the slab-subbase interface, then the magnitude of frictional resistance is immediately dependent on slab weight.

8. A polythene sheet tends to be a very efficient friction reducer whenever a polythene sheet is used between a subbase and a slab; without it, the bond between SMG and slab will be solid and resist more force.

9. $20 \mathrm{~cm}$ thick slab with rough interface is recommended if the facility required high coefficient of friction under rigid pavement.

\section{Acknowledgements}

The researchers are thankful to the Mustansiriyah University, Faculty of Engineering, Road and Transport Department, regarding their assistance and guidance to fulfill this research's humble study. This thesis did not obtain any particular fund from supporting organizations, private, or not-for-profit sectors in the contained of this research.

\section{Conflict of Interest}

The authors confirm that the publication of this article causes no conflict of interest.

\section{References}

1. Wesevich, J., McCullough, B., \& Burns, N. (1987). "STABILIZED SUBBASE FRICTION STUDY FOR CONCRETE PAVEMENTS”. INTERIM REPORT. Retrieved from https://t.ly/CwGE

2. Diaz, A., Burns, N., \& McCullough, B. (1986). "BEHAVIOR OF LONG PRESTRESSED PAVEMENT SLABS AND DESIGN METHODOLOGY”. Research Report 401-3, Center for Transportation Research, The University of Texas at Austin, November 1986. Retrieved from http://t.1y/n9TM

3. Oladiran, O. G. (2014). "Assessment of restrained shrinkage cracking of concrete through elliptical rings". Brunel University School of Engineering and Design $\mathrm{PhD}$ Theses, Retrieved from http://bura.brunel.ac.uk/handle/2438/8224

4. Jeong, J.-H., Park, J.-Y., Lim, J.-S., \& Kim, S.-H. (2014). "Testing and modelling of friction characteristics between concrete slab and subbase layers". Road Materials and Pavement Design", 15(1),1141-130. https://doi.org/10.1080/14680629.2013.863 $\underline{161}$

5. Maitra, S., Reddy, K., \& Ramachandra, L. (2009). "Experimental evaluation of interface friction and study of its influence on concrete pavement response". Journal of transportation engineering, 135(8), 563571.http://t.ly/AEIw

6. Al-Fahdawi, J. Z., \& Banyhussan, Q. S. (2020). "Optimization of Eco-friendly Pavement Concrete Mixture Using Response Surface Methodology”. Paper presented at the IOP Conference Series: Materials Science and Engineering. https://t.ly/OXNk

7. SCRB. (2003). "General Specifications for Roads and Bridges, Ministry of Housing and construction”, Iraq.https://t.ly/G27O 
8. Al-Fahdawi, J. Z. (2020). "USING ECOFRIENDLY CONCRETE MIXTURE FOR MINIMUM CRACKS RISK IN CONCRETE PAVEMENT AT EARLY-AGE”. (89). Mustansiriyah University, Retrieved from (Special_Issue_2020).http://t.ly/yK1Z

9. Timms, A. G. (1963). "Evaluating subgrade friction-reducing mediums for rigid pavements". Highway Research Record, 60, 28-38.

10. Abdulridha, M. A., Salman, M. M., \& Banyhussan, Q. S. (2020). "Prediction the Strength of Fibered Reinforced Concrete Pavement Using Response Surface Methodology: Parametric Study". Paper presented at the IOP Conference Series: Materials Science and Engineering.https://doi.org/10.1088/1757899X/881/1/012180 